\title{
Kaurene Diterpenes and Other Chemical Constituents from Mikania stipulacea (M. Vahl) Willd.
}

\author{
Andréa M. do Nascimento and Dionéia C. R. de Oliveira* \\ Departamento de Física e Química, Faculdade de Ciências Farmacêuticas de Ribeirão Preto, \\ Universidade de São Paulo, Via do Café s/n, 14040-903, Ribeirão Preto - SP, Brazil

\begin{abstract}
O estudo fitoquímico de Mikania stipulacea conduziu ao isolamento e à identificação de lupeol, $\alpha$-amirina, estigmasterol, $\beta$-sitosterol, campesterol, 3-O- $\beta$-D-glicopiranosil estigmasterol, 3-O- $\beta$ D-glicopiranosil sitosterol, da cumarina isoescopoletina e dos ácidos vanílico, cinamoilgrandiflórico e ent-caurenóico, juntamente com dois diterpenos novos, os ácidos ent-9 $\alpha$-hidroxi-15 $\beta$-E-cinamoiloxi16-cauren-19-óico e ent-9 $\alpha$-hidroxi-15 $\beta$-Z-cinamoiloxi-16-cauren-19-óico. Estas substâncias foram identificadas com base na análise dos espectros de IV, EM e RMN de ${ }^{1} \mathrm{H} \mathrm{e}{ }^{13} \mathrm{C}$.
\end{abstract}

\begin{abstract}
Phytochemical study of Mikania stipulacea yielded lupeol, $\alpha$-amyrin, stigmasterol, $\beta$-sitosterol, campesterol, $\beta$-sitosteryl glucopyranoside, stigmasteryl glucopyranoside, the coumarin isoscopoletin, and vanillic, cinnamoylgrandifloric and ent-kaurenoic acids, besides two new diterpene acids: ent-9 $\alpha$-hydroxy-15 $\beta$-E-cinnamoyloxy-16-kauren-19-oic and ent-9 $\alpha$-hydroxy-15 $\beta$ Z-cinnamoyloxy-16-kauren-19-oic. IR, ${ }^{1} \mathrm{H}$ and ${ }^{13} \mathrm{C}$ NMR and MS spectroscopic analyses were used for the identification of these compounds.
\end{abstract}

Keywords: Mikania stipulacea, Asteraceae, diterpenes, ent-kaurenes

\section{Introduction}

The tribe Eupatorieae forms the major part of the Asteraceae family and comprises nearly 2,400 species $^{1,2}$. Mikania Willd is the only genus in the sub-tribe Mikaniinae of Eupatorieae. These species are native to Central and South America, where they are known as "guaco" and used to treat fever, rheumatism, flu and respiratory tract diseases ${ }^{3,4}$. As might be expected for such a large and diverse genus, its chemistry is also diverse ${ }^{5}$. Less than $10 \%$ of the more than 430 known Mikania species have been studied. Sesquiterpene lactones are found in nearly two thirds of these species $^{5}$. In the other species whose chemistry has been investigated, diterpenes, mainly of the ent-kaurene type, predominate ${ }^{6}$.

Continuing our work on this genus ${ }^{7,8}$ we report herein the isolation of two new kaurene-type diterpenes from $M$. stipulacea. Their structures were proposed on the basis of spectroscopic data and comparisons of the attributed signals with previously published data on related compounds.

\section{Experimental}

\section{General}

The IR spectra were obtained on $\mathrm{KBr}$ pellets in a Perkin
Elmer model 1420 spectrophotometer. ${ }^{1} \mathrm{H}$ NMR $(300 \mathrm{MHz})$ and ${ }^{13} \mathrm{C}$ NMR $(75 \mathrm{MHz})$ spectra were recorded on a Bruker DPX 300 in $\mathrm{CDCl}_{3}$ with TMS as internal standard. EIMS was obtained at $70 \mathrm{eV}$ on HP 5988-A. Optical rotations were measured with a Polartronic HH8. Prep. TLC was carried out on Si gel PF-254 (Merck), CC on Si gel 60 (0.063 a 0.200) (Merck) and VLC on Si gel 60 H (0.005 - 0.045) (Merck).

\section{Plant material}

Mikania stipulacea (M. Vahl) Willd was collected in Restinga de Maricá, Rio de Janeiro, RJ, Brazil, in July, 1996, and identified by Professor Dr. Janie G. Silva (Instituto de Biologia da Universidade Federal Fluminense - Rio de Janeiro). A voucher specimen (SPFR 04123) was deposited in the herbarium of the Department of Biology, FFCLRP/ USP and was used for the authentication of the species.

\section{Extraction and fractionation}

Dried and powdered whole $M$. stipulacea plants $(1.7 \mathrm{~kg})$ were exhaustively extracted at room temperature with hexane, ethyl acetate and ethanol. Evaporation of the solvents under reduced pressure furnished $46.0 \mathrm{~g}, 23.0 \mathrm{~g}$ and $225.0 \mathrm{~g}$ respectively, of crude extracts. The bulk of each extract (45.0 $\mathrm{g}$ hexane, $22.0 \mathrm{~g}$ ethyl acetate, $60.0 \mathrm{~g}$ ethanol) was chromatographed separately over silica gel under vacuum 
(VLC) and eluted with hexane, gradually increasing the polarity with ethyl acetate and then methanol.

From the crude hexane extract, 14 fractions were collected after VLC.

Fraction 3 was precipited from $\mathrm{MeOH}$, giving $1.0 \mathrm{~g}$ of solid. CC of solid (3A) on silica gel with hexane and gradually increasing the polarity with ethyl acetate and then methanol, yielded 22 subfractions: Subfr. 3A.6 yielded 79.0 mg of crystals which were recrystallized from hexane-ethyl acetate $(98: 2)$ and gave a mixture of lupeol and $\alpha$-amyrin (69.0 mg); Subfr. 3A.9 (99.0 mg) was also recrystallized from hexane-ethyl acetate (98:2) to provide a mixture of $\beta$-sitosterol, stigmasterol and campesterol (49.2 mg); Subfr. 3A.12 (43.0 mg) was purified by prep. TLC (hexane-ethyl acetate 85:15) affording $10.0 \mathrm{mg}$ of cinnamoylgrandifloric acid. Methanol-soluble fr. 3B (600.0 $\mathrm{mg}$ ) was purified by $\mathrm{CC}$ on silical gel with hexane and increasing amounts of ethyl acetate and methanol, affording 16 subfractions: ent-16-Kauren-19-oic acid $(5.0 \mathrm{mg})$ and a mixture of $\beta$-sitosterol, stigmasterol and campesterol $(3.0 \mathrm{mg})$ were obtained from subfr. 3B.5 (100.0 mg) after prep. HPLC (Si-60 column, using Hexane-iso-propyl alcohol 98:2).

Fraction 4 (2.0 g) was purified by consecutive CCs (silica gel) to give subfr. $4.10 .8(30.0 \mathrm{mg})$, which, when submitted to prep. HPLC (Si-60 column, using Hexaneiso-propyl alcohol 97:3), yielded a mixture of compounds $\mathbf{1}$ and $\mathbf{2}$ (5 $\mathrm{mg})$.

Fraction 5 (1.3 g) was separated by CC (silica gel) into 16 subfractions: Subfr. $5.8(50.0 \mathrm{mg})$ eluting with hexaneethyl acetate 1:1 after prep. TLC (silica gel) yielded compound 1 ( $3.0 \mathrm{mg})$.

Finally, fraction $10(500.0 \mathrm{mg})$ after CC on silica gel (hexane-ethyl acetate and methanol in mixtures of increasing polarity) and precipitation in ethyl acetate of subfr. 10.6 led to the isolation of a mixture of $\beta$-sitosteryl glucopyranoside and stigmasteryl glucopyranoside $(4.0 \mathrm{mg})$.

From the crude ethyl acetate extract, 15 fractions were collected after VLC.

Fractions 4 and 5 were pooled (3.44 g) and chromatographed over a silica gel column (CC) eluted with hexane, gradually increasing the polarity with ethyl acetate and then methanol. Subfrs. 4/5.12 (100.0 mg) and 4/5.17 $(84.0 \mathrm{mg})$ were submitted to prep. TLC (silica gel), eluting with hexane-ethyl acetate $1: 1$, to afford compound $\mathbf{1}$ (17.0 $\mathrm{mg}$ ) and isoscopoletin $(1.0 \mathrm{mg})$, respectively.

CC of fraction $6(500.0 \mathrm{mg})$ on silica gel (hexane, ethyl acetate and methanol in a mixture of increasing the polarity) followed by precipitation (methanol) of subfr. 6.15 (41.0 $\mathrm{mg}$ ) yielded a vanillic acid (3.0 $\mathrm{mg})$.

Fractions 8, 9, 10, 11 and 12 after precipitation in ethyl acetate yielded a mixture of $\beta$-sitosteryl glucopyranoside and stigmasteryl glucopyranoside (1.3 g).

From the crude ethanol extract, 15 fractions were collected after VLC.

Fractions 3, 4 and 5 were combined $(351.0 \mathrm{mg})$ and dissolved in acetonitrile. The soluble part (subfr. 3/4/5-C, $281.0 \mathrm{mg}$ ) was submitted to prep. HPLC (Si-60 column, using hexane-iso-propyl alcohol 97:3), yielding a compound 1 ( $2.0 \mathrm{mg})$.

Frs. 6 and 7 showed similarity on TLC and were pooled (50.0 mg) and submitted to prep. TLC (silica gel), yielding isoscopoletin $(3.0 \mathrm{mg})$.

Ent-9 $\alpha$-hydroxy-15 $\beta$-E-cinnamoyloxy-16-kauren-19oic acid (1): colourless crystals (not sufficient to obtain a sharp $\mathrm{mp}$ but homogeneous by TLC in several solvent systems $) \cdot[\alpha]_{\mathrm{D}}{ }^{25}-0.14^{\circ}\left(c \quad 1.508 \times 10^{-3}, \mathrm{CHCl}_{3}\right)$; IR: $\left(v_{\max } / \mathrm{cm}^{-1}\right) 3600$ - $2600(\mathrm{OH}$ acid $), 3500(\mathrm{OH}), 1690$, $1720(\mathrm{C}=\mathrm{O}), 1630(\mathrm{C}=\mathrm{C})(\mathrm{KBr})$; EIMS, $m / z$ (relative intensity in \%): $298\left[(\mathrm{M}-148)-\mathrm{H}_{2} \mathrm{O}\right]^{+}(19), 161[(\mathrm{M}-$ 148) $\left.-\mathrm{H}_{2} \mathrm{O}-137\right]^{+}(46), 131[\mathrm{M}-333]^{+}(100), 148[\mathrm{M}-$ $316]^{+}(60), 103[131-\mathrm{CO}]^{+}(55) .{ }^{1} \mathrm{H}$ NMR $(300 \mathrm{MHz}$, $\mathrm{CDCl}_{3}$ ), see Table $1 .{ }^{13} \mathrm{C}$ NMR (PND, DEPT $135^{\circ}$ and HMQC for correlating directly bonded ${ }^{1} \mathrm{H}$ and ${ }^{13} \mathrm{C}$ nuclei (75 $\mathrm{MHz}, \mathrm{CDCl}_{3}$ ), see Table 2 .

Ent-9 $\alpha$-hydroxy-15 $\beta$-Z-cinnamoyloxy-16-kauren-19oic acid (2), unseparated from 1: colourless gum; ${ }^{1} \mathrm{H}$ NMR (300 MHz, $\mathrm{CDCl}_{3}$ ), see Table $1 .{ }^{13} \mathrm{C}$ NMR (PND, DEPT $135^{\circ}$ and $\mathrm{HMQC}$ for correlating directly bonded ${ }^{1} \mathrm{H}$ and ${ }^{13} \mathrm{C}$ nuclei $\left(75 \mathrm{MHz}, \mathrm{CDCl}_{3}\right.$ ), see Table 2 .

\section{Results and Discussion}

Whole $M$. stipulacea plants were extracted with hexane, ethyl acetate and ethanol. The chromatographic fractionation of these extracts yielded stigmasterol, $\beta$-sitosterol and campesterol, cinnamoylgrandifloric ${ }^{9}$, entkaurenoic $\operatorname{acid}^{10,11}$, vanillic acid ${ }^{12}$, isoscopoletin ${ }^{13}$, lupeol $^{14}, \alpha$-amyrin ${ }^{14}, \beta$-sitosteryl glucopyranoside and stigmasteryl glucopyranoside ${ }^{15}$. The above compounds were individually identified by spectroscopic analyses and comparisons with reported data.

The ent-kaurene diterpene $\mathbf{1}$, obtained as a pure solid exhibited a ${ }^{1} \mathrm{HNMR}$ spectrum with typical signals of the ester $E$-cinnamate, $\delta 7.69 \mathrm{~d}$ and $6.46 \mathrm{~d}$ (AB system, $J_{\mathrm{AB}}$ $16 \mathrm{~Hz}$ ). The $\mathrm{H}-15$ exhibited an even higher paramagnetic shift when compared with the H-15 chemical shift of entkaurenoic acid (3) ( $\delta$ 2.09) and of cinnamoylgrandifloric acid (4) ( $\delta$ 5.41), (Table 1$)$. The stereochemistry at C-9 and $\mathrm{C}-15$ was deduced from the chemical shift of $\mathrm{H}-15$ which could be explained only by a deshielding effect of a $\beta$-oriented oxygen function in C-9. 
Table 1. ${ }^{1} \mathrm{H}$ NMR data $(\delta)$ for $\mathbf{1}$ and $\mathbf{2}$ in $\mathrm{CDCl}_{3}$ at $300 \mathrm{MHz}$ compared with $\mathbf{3}\left(\mathrm{CDCl}_{3}\right)^{10}$ and $\mathbf{4}\left(\mathrm{CDCl}_{3}\right)^{9}$.

\begin{tabular}{|c|c|c|c|c|}
\hline $\mathrm{H}$ & $\mathbf{1}$ & 2 & 3 & 4 \\
\hline 2 ' & $6.46 \mathrm{~d}(16 \mathrm{~Hz})$ & $5.96 \mathrm{~d}(12.8 \mathrm{~Hz})$ & - & $6.47 \mathrm{~d}(16 \mathrm{~Hz})$ \\
\hline $3^{\prime}$ & $7.69 \mathrm{~d}(16 \mathrm{~Hz})$ & $6.96 \mathrm{~d}(12.8 \mathrm{~Hz})$ & - & $7.69 \mathrm{~d}(16 \mathrm{~Hz})$ \\
\hline $5^{\prime}, 9^{\prime}$ & $7.32-7.63 \mathrm{~m}$ & $7.32-7.63 \mathrm{~m}$ & - & $7.53 \mathrm{~m}$ \\
\hline $6^{\prime}, 7^{\prime}, 8^{\prime}$ & $7.32-7.63 \mathrm{~m}$ & $7.32-7.63 \mathrm{~m}$ & - & $7.38 \mathrm{~m}$ \\
\hline 13 & 2.82 br s & 2.74 br s & 2.62 br s & 2.82 br s \\
\hline 15 & 6.08 br s & 6.08 br s & 2.09 br s & 5.41 br s \\
\hline 17 & 5.16 br s & 5.16 br s & 4.79 br s & 5.07 br s \\
\hline $17^{\prime}$ & 5.19 br s & 5.19 br s & 4.79 br s & 5.20 br s \\
\hline Me-18 & $1.23 \mathrm{~s} 6$ & $1.23 \mathrm{~s}$ & $1.24 \mathrm{~s}$ & $1.21 \mathrm{~s}$ \\
\hline $\mathrm{Me}-20$ & $1.11 \mathrm{~s} 6$ & $1.07 \mathrm{~s}$ & $0.95 \mathrm{~s}$ & $0.99 \mathrm{~s}$ \\
\hline
\end{tabular}

Table 2. ${ }^{13} \mathrm{C}$ NMR data $(\delta)$ for 1 and 2 in $\mathrm{CDCl}_{3}$ at $75 \mathrm{MHz}$ compared with $4\left(\mathrm{CDCl}_{3}\right)^{9}, \mathbf{5}\left(\mathrm{C}_{5} \mathrm{D}_{5} \mathrm{~N}\right)^{17}$ and $\mathbf{6}\left(\mathrm{C}_{5} \mathrm{D}_{5} \mathrm{~N}\right)^{18}$.

\begin{tabular}{|c|c|c|c|c|c|}
\hline$C$ & 1 & 2 & 4 & 5 & 6 \\
\hline 1 & $37.9 \mathrm{t}$ & $37.9 \mathrm{t}$ & $40.7 \mathrm{t}$ & $36.8 \mathrm{t}$ & $38.7 \mathrm{t}$ \\
\hline 2 & $18.9 \mathrm{t}$ & $18.9 \mathrm{t}$ & $18.5 \mathrm{t}$ & $19.9 \mathrm{t}$ & $19.8 \mathrm{t}$ \\
\hline 3 & $37.9 \mathrm{t}$ & $37.9 \mathrm{t}$ & $37.8 \mathrm{t}$ & $38.6 \mathrm{t}$ & $36.4 \mathrm{t}$ \\
\hline 4 & $44.5 \mathrm{~s}$ & $44.5 \mathrm{~s}$ & $43.8 \mathrm{~s}$ & $44.0 \mathrm{~s}$ & $43.9 \mathrm{~s}$ \\
\hline 5 & $49.8 \mathrm{~d}$ & $49.8 \mathrm{~d}$ & $56.7 \mathrm{~d}$ & $49.8 \mathrm{~d}$ & $57.2 \mathrm{~d}$ \\
\hline 6 & $20.8 \mathrm{t}$ & $20.8 \mathrm{t}$ & $20.9 \mathrm{t}$ & $22.7 \mathrm{t}$ & $22.0 \mathrm{t}$ \\
\hline 7 & $33.8 \mathrm{t} *$ & $33.8 \mathrm{t} * *$ & $34.9 \mathrm{t}$ & $40.8 \mathrm{t}$ & $41.2 \mathrm{t}$ \\
\hline 8 & $53.1 \mathrm{~s}$ & $53.1 \mathrm{~s}$ & $47.7 \mathrm{~s}$ & $49.8 \mathrm{~s}$ & $48.4 \mathrm{~s}$ \\
\hline 9 & $76.8 \mathrm{~s}$ & $77.2 \mathrm{~s}$ & $53.1 \mathrm{~d}$ & $76.9 \mathrm{~s}$ & $54.0 \mathrm{~d}$ \\
\hline 10 & $43.8 \mathrm{~s}$ & $43.8 \mathrm{~s}$ & $40.0 \mathrm{~s}$ & $44.5 \mathrm{~s}$ & $40.2 \mathrm{~s}$ \\
\hline 11 & $29.2 \mathrm{t}$ & $29.2 \mathrm{t}$ & $19.1 \mathrm{t}$ & $29.5 \mathrm{t}$ & $18.7 \mathrm{t}$ \\
\hline 12 & $32.1 \mathrm{t}$ & $32.1 \mathrm{t}$ & $32.7 \mathrm{t}$ & $32.9 \mathrm{t}$ & $33.1 \mathrm{t}$ \\
\hline 13 & $41.2 \mathrm{~d}$ & $41.2 \mathrm{~d}$ & $42.7 \mathrm{~d}$ & $42.9 \mathrm{~d}$ & $42.9 \mathrm{~d}$ \\
\hline 14 & $37.4 \mathrm{t}^{*}$ & $37.4 \mathrm{t}^{* *}$ & $37.4 \mathrm{t}$ & $34.6 \mathrm{t}$ & $36.7 \mathrm{t}$ \\
\hline 15 & $79.2 \mathrm{~d}$ & $79.2 \mathrm{~d}$ & $83.2 \mathrm{~d}$ & $44.4 \mathrm{t}$ & $82.7 \mathrm{~d}$ \\
\hline 16 & $154.8 \mathrm{~s}$ & $154.8 \mathrm{~s}$ & $155.4 \mathrm{~s}$ & $156.3 \mathrm{~s}$ & $161.3 \mathrm{~s}$ \\
\hline 17 & $110.4 \mathrm{t}$ & $110.4 \mathrm{t}$ & $110.1 \mathrm{t}$ & $102.9 \mathrm{t}$ & $117.8 \mathrm{t}$ \\
\hline 18 & $28.9 \mathrm{q}$ & $28.9 \mathrm{q}$ & $28.9 \mathrm{q}$ & $29.6 \mathrm{q}$ & $29.3 \mathrm{q}$ \\
\hline 19 & $183.0 \mathrm{~s}$ & $183.0 \mathrm{~s}$ & $184.2 \mathrm{~s}$ & $180.7 \mathrm{~s}$ & $180.3 \mathrm{~s}$ \\
\hline 20 & $17.4 \mathrm{q}$ & $17.4 \mathrm{q}$ & $15.94 \mathrm{q}$ & $18.0 \mathrm{q}$ & $16.3 \mathrm{q}$ \\
\hline 1 , & $167.1 \mathrm{~s}$ & $167.1 \mathrm{~s}$ & $166.9 \mathrm{~s}$ & & \\
\hline 2 ' & $118.4 \mathrm{~d}$ & $120.0 \mathrm{~d}$ & $118.6 \mathrm{~d}$ & & \\
\hline 3 , & $144.9 \mathrm{~d}$ & $143.5 \mathrm{~d}$ & $144.7 \mathrm{~d}$ & & \\
\hline 4, & $134.5 \mathrm{~s}$ & $134.5 \mathrm{~d}$ & $134.6 \mathrm{~s}$ & & \\
\hline 5 , & $128.1 \mathrm{~d}$ & $128.9 \mathrm{~d}$ & $128.8 \mathrm{~d}$ & & \\
\hline 6 , & $128.9 \mathrm{~d}$ & $127.9 \mathrm{~d}$ & $128.1 \mathrm{~d}$ & & \\
\hline 7 , & $130.3 \mathrm{~d}$ & $129.9 \mathrm{~d}$ & $130.1 \mathrm{~d}$ & & \\
\hline 8, & $128.9 \mathrm{~d}$ & $127.9 \mathrm{~d}$ & $128.1 \mathrm{~d}$ & & \\
\hline 9, & $128.1 \mathrm{~d}$ & $128.9 \mathrm{~d}$ & $128.8 \mathrm{~d}$ & & \\
\hline
\end{tabular}

*,** Assignments may be interchanged

A comparison of the ${ }^{13} \mathrm{C}$ NMR spectral data of $\mathbf{1}$ and $\mathbf{4}$ showed that the hydroxyl group at C-9 in $\mathbf{1}$ produced a deshielding effect on the signals of C-8, C-10 and C-11 and a shielding effect on the signals of C-1, C-5, C-7 and C-12 ( $\gamma-$ gauche effect), thus confirming the position and the stereochemistry proposed earlier for C-9 (Table 2). In accordance with this conclusion, the ${ }^{13} \mathrm{C}$ NMR data of $\mathbf{1}$ were similar to those for ent-9 $\alpha$-hydroxy-16-kauren-19-oic acid (5). Some differences were due to the additional O-cinnamoyl group at C15 , which caused a strong high frequency shift of this carbon. In addition, direct comparison of $\mathbf{1}$ with $\mathbf{4}$ and grandifloric acid (6), in which the C-9 (without the hydroxyl group) appears respectively at $\delta 53.1$ and 54.0, confirmed the kaurene skeleton with an O-cinnamoyl group at C-15 and an $\mathrm{OH}$ group at C-9.
The axial trans position of the $\mathrm{C}-19$ carboxyl group in relation to $\mathrm{H}-5$ was deduced from the chemicals shifts of C-5, C-18, C-19 and C-2016.

The ent series of compound $\mathbf{1}$ was established by measurement of the optical rotation. The structure was confirmed by MS and IR data.

The diterpene 2 was obtained mixed with compound 1. The presence of the $E$ and $Z$-cinnamate esters in the diterpenes was suggested by the observation of their typical signals, respectively, at $\delta 7.69 \mathrm{~d}$ and $6.46 \mathrm{~d}$ (AB system, $J_{\mathrm{AB}} 16 \mathrm{~Hz}$ ) and $\delta 6.96 \mathrm{~d}$ and $5.96 \mathrm{~d}\left(\mathrm{AB}\right.$ system, $J_{\mathrm{AB}} 12.8$ $\mathrm{Hz})$ in their ${ }^{1} \mathrm{HNMR}$ spectrum. 1 and 2 were $2^{\prime}, 3^{\prime}-$ E/Z isomers which could be identified by their different chemical shifts and couplings. 
On the basis of the present data, we conclude that $M$. stipulacea belongs to a fairly large group of Brazilian Mikania species which produce ent-kauranes rather than sesquiterpene lactones 5,7 .
18

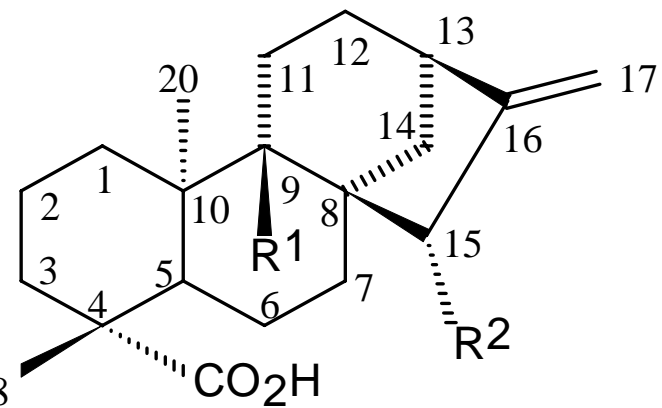

19<smiles>O=C(O)C=Cc1ccccc1</smiles>

2: $\quad \mathrm{R}^{1}=\mathrm{OH}$

$\mathrm{R}^{2}=$

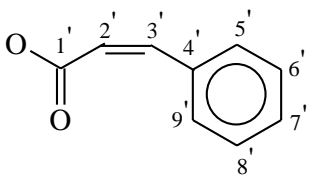

3: $\quad \mathrm{R}^{1}=\mathrm{H}$

$\mathrm{R}^{2}=$

$\mathrm{H}-2$

4: $\quad \mathrm{R}^{1}=\mathrm{H}$

$\mathrm{R}^{2}=$

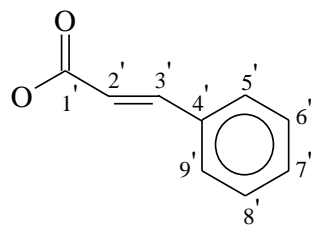

5: $\quad \mathrm{R}^{1}=\mathrm{OH}$

$\mathrm{R}^{2}=\mathrm{H}-2$

6: $\quad \mathrm{R}^{1}=\mathrm{H}$

$\mathrm{R}^{2}=\mathrm{OH}$

\section{Acknowledgements}

We thank Fundação de Amparo à Pesquisa do Estado de São Paulo (FAPESP) for financial aid and a fellowship to A.M.N.

\section{References}

1. Bremer, K. In Asteraceae Cladistics \& Classification; Bremer, K., Ed.; Timber Press; Portland, Oregon, 1994, p 625.

2. King, R. M.; Robinson, H. In The Genera of the Eupatorieae (Asteraceae); King, R.M.; Robinson, H., Eds.; Allen Press, Inc.; Lawrence, Kansas, 1987, 22, p 416.

3. Oliveira, F.; Alvarenga, M. A .; Akisue, M. K. Rev. Farm. Bioquím. Univ. S. Paulo 1984, 20, 169.

4. Vilegas, J. H. Y.; Marchi, E.; Lanças, F. M. Phytochem. Anal. 1997, 8, 74.

5. Herz, W. J. Indian Chem. Soc. 1998, 75, 559.

6. Lobitz, G. O.; Tamayo-Castillo, G.; Poveda, L.; Merfort, I. Phytochemistry 1998, 49, 805.

7. Fabbri, H.; Oliveira, D. C. R.; Vichnewski, W.; Herz, W. Biochem. Syst. and Ecol. 1997, 25, 563.

8. Veneziani, R. C. S.; Oliveira, D. C. R. Biochem. Syst. and Ecol. 1999, 27, 99.

9. Vichnewski, W.; Leitão Filho, H. F.; Murari, R.; Herz, W. Phytochemistry 1977, 16, 2028.

10. Dev. S.; Misra, R. In CRC Handbook of Terpenoids; Dev, S., Ed.; CRC Press, Inc.; Boca Raton, Florida, 1986, IV, p 285.

11. Yamasaki, K.; Kohda, H.; Kobayashi, T.; Kasai, R.; Tanaka, O. Tetrahedron Lett. 1976, 13, 1005.

12. Sasaki, S. In Handbook of Proton-NMR Spectra and Data; Asahi Research Center Co., Ltd., Ed.; Academic Press, Inc.; Tokio, 1985, 3, p 110.

13. Razdan, T. K.; Qadri, B.; Harkar, S.; Waight, E. S. Phytochemistry 1987, 26, 2063.

14. Mahato, S. B.; Kundu, A. P. Phytochemistry 1994 37, 1517.

15. Kojima, H.; Sato, N.; Hatano, A.; Ogura, H. Phytochemistry 1990, 29, 2351.

16. Velandia, J. R.; Carvalho, M. G.; Braz-Filho, R. Quím. Nova 1998, 21, 397.

17. Murakami, T.; Iida, H.; Tanaka, N.; Saiki, Y.; Chen, C-M.; Iitaka, Y. Chem. Pharm. Bull. 1981, 29, 657.

18. Ohno, N.; Mabry, T. J. Phytochemistry 1980, 19, 609.

Received: March 28, 2000

Published on the web: May 21, 2001

FAPESP helped in meeting the publication costs of this article. 